\title{
Mechanism of Oxygenation of 2,6-Di-tert-butylphenol Derivative
}

\author{
Jaehwi Lee, ${ }^{\dagger}$ Jong-In Choe, ${ }^{*}$ Seokwon Jung, ${ }^{;}$and Seung Wook Ham ${ }^{4+*}$ \\ "College of Pharmacy. "Deparment of Chemistry, Chung-Ang University, Seout 156-756, Korea. "E-mail: swham(a)canac.kr \\ Received November I, 2005
}

Key Words : Phenoxide anion, Autoxidation, Electron transfer mechanism, Semi-empirical calculation

The base-catalyzed oxygenation of phenol or naphthol derivatives has been of interest in both biological and synthetic system. ${ }^{1-x}$ In general, when phenoxide anions 1 are exposed to triplet molecular oxygen, the corresponding epoxy alcohols 7 are formed in nearly quantitative yield. Possible reaction pathway for the oxidation process is proposed as shown in Scheme 1. ${ }^{7 . x}$ Reaction of the phenoxide anions 1 and molecular oxygen results in the peroxides 4 , which then undergo intramolecular conjugate addition to form the dioxetane enolate anions $\mathbf{5}$. Finally, dioxetane ring opening by nucleophilic displacement yields the epoxy alcohols 6 . However, the reaction pathway of molecular oxygen and phenoxide anions 1 to form the peroxides 4 might be unfavorable because the singlet phenolate anions 1 cannot react in a single step with triplet molecular oxygen to yield the singlet products."

To overcome the spin-forbidden rule, two possible mechanisıns of base-catalyzed oxygenation of phenol derivatives have been proposed. "' One is a charge transfer mechanism (pathway 1), where the phenolate anion 1 interacts with $\pi$ orbital of molecular oxygen to afford a triplet charge transfer complex 2 . The complex then experiences intersystem crossing $i . e_{\text {, }}$ one of unpaired electrons undergoes the spin inversion from the triplet charge transfer complex to the singlet complex, giving a singlet oxygen. Alternative pathway is an electron transfer mechanism (pathway 2). The phenoxide anions 1 react with molecular oxygen to give the phenoxyl radicals 3 and superoxide by one-electron transfer. The phenoxyl radicals $\mathbf{3}$ then trap superoxide to yield the peroxy anions 4. Here we report theoretical and experimental investigations of the possible intemnediate involved in the base-catalyzed oxygenation of phenol derivative.

Previously, we synthesized the cyclopropyl derivative 8 of 2.6-di-tert-butylphenol to distinguish phenoxide anion 11 from the phenoxy radical $\mathbf{1 2}$ in the course of autoxidation" because rearrangement of the cyclopropyl radical to homoallylcarbinyl radical was thought to be effective in the shortlived radical trap. ${ }^{12}$ When a solution of potassium phenolate 9 in tetrahydrofuran was stirred under an atmosphere of oxygen at room temperature, the corresponding epoxy alcohol 10 was formed and no ring-opened product $\mathbf{1 4}$ was detected in the reaction mixtures. Therefore, we suggested a charge transfer mechanism describing the action of basecatalyzed oxygenation of phenols.

Although it has been suggested that $\alpha$-cyclopropylbenzyl radicals undergo fairly rapid rearrangement, ${ }^{12}$ little is known about the stabilities of cyclopropylcarbinyl radical 12 with the radical-stabilizing group and homoallylcarbinyl radical 13. Interestingly, in this study, our semi-empirical calculation using AM1 indicated that the Gibbs free energies of radical 12 and radical 13 are $-4266.39 \mathrm{kcal} / \mathrm{mol}$ and $-4265.70 \mathrm{kcal} /$ mol, respectively, showing that the free energy change of rearrangement is endothermic by $0.69 \mathrm{kcal} / \mathrm{mol}$. This result suggests that ring-opening of $\mathbf{1 2}$ can not be only reversible but that equilibrium may favor the ring closed form, and the radical probe 8 might give an unclear guide to charge transfer mechanism in the previous work. "To examine whether singlet oxygen was really produced via energy transfer, we then carried out the oxygenation reaction of potassium phenolate 9 in the presence of 1,4-diazbicyclo[2.2,2]octane(Dabco), which has been known to inhibit singlet oxygen reactions but has little effect on free radical reactions. However, addition of Dabco did not have any influence, indicating that singlet oxygen was not a primary oxidizing species in the base-catalyzed autoxidation.

Regarding electron transfer from the phenoxide anion to molecular oxygen (pathway 2), it has been proposed that superoxide ion does not couple with 2,6-di-tert-butylphenoxy radicals but reduces radicals to give the corresponding phenoxide anions, and mechanism involving for the base-

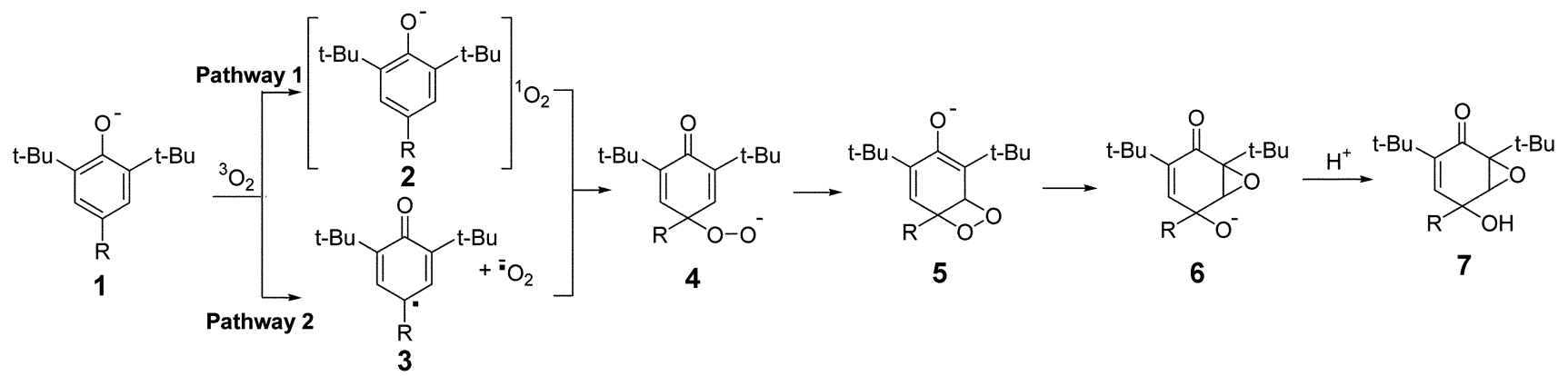




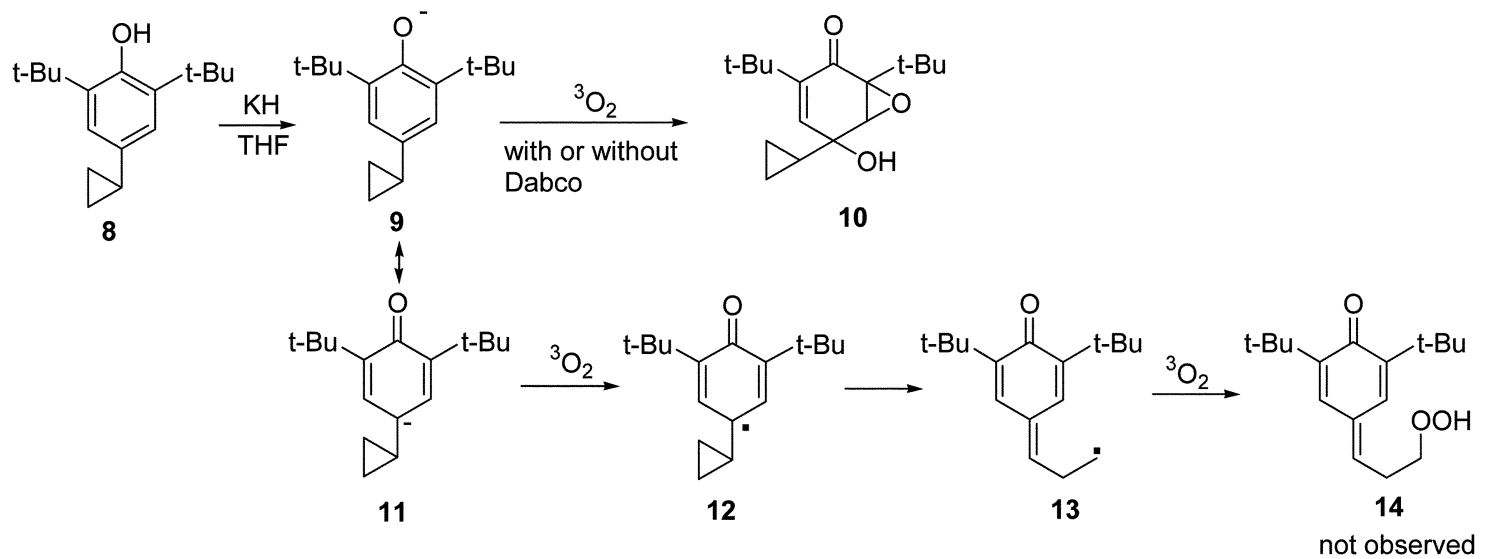

Scheme 2

catalyzed oxygenation of 2,6-di-fert-butylphenols is an ionic process. ${ }^{13}$ Therefore, the second control experiment was carried out by treating the phenoxide anion 9 with ${ }^{18} \mathrm{O}_{2}$. After ${ }^{18} \mathrm{O}_{2}$ [96\% enriched in 18-oxygen (ICON), $100 \mathrm{~mL}$ ] was delivered to a solution of 9 from a sealed tube, the mass spectrum reveals that two atoms of ${ }^{18} \mathrm{O}$ have been incorporated into the hydroxyl group and epoxide of the product 10. However, when the ${ }^{18} \mathrm{O}$ label was employed with exeess $\mathrm{KO}_{2}$ in presenec of 18 -crown- 6 , the peak at $m / 2278$ in the mass spectrum of product is $21 \%$ as intense as the peak at $m / z 282$. If superoxide can not couple with phenoxyl radical 12, the molecular ion of the product will consist of only ion cluster at $m / z 282$ corresponding to incorporation of two atoms of ${ }^{18} \mathrm{O}$ from ${ }^{18} \mathrm{O}_{2}$. Although the fractional amount of unlabeled product was produced because of the $\mathrm{KO}_{2}$ solubility or the fast rebound reaction with newly synthesized superoxide-18, the decrease of ${ }^{18} \mathrm{O}$ in the epoxy alcolol 10 from the labeling experiment indicates the possibility of superoxide coupling, and this is most reasonably ascribed to the phenoxy radical mechanism (pathway 2 ).

The relative one-electron reduction potential of phenoxide anion controls the position of the equilibrium. The equilibrium constant is approximately $10^{\Delta f(0): 06}$, where $\Delta E=\mathrm{E}\left(\mathrm{O}_{2} /\right.$ superoxide) - E(phenoxy radical/phenoxide anion) and the potentials are in volts. Reduction potential of oxygen is $-0.82 \mathrm{~V}$

$$
\mathrm{Ph}_{-} \mathrm{O}^{-}+\mathrm{O}_{2} \rightleftharpoons \mathrm{Ph}-\mathrm{O}^{+}+\mathrm{O}_{2}^{-}
$$

vs SCE in $\mathrm{CH}_{3} \mathrm{CN}^{14}$ and one-electron reduction potential of phenoxy radical is about $-0.29 \mathrm{~V}$ is $\mathrm{SCE}$ in $\mathrm{CH}_{3} \mathrm{CN}^{15}$ Therefore, the overall potential for electron transfer of phenoxide anion to oxygen is about $-0.5 \mathrm{~V}$ implying an unfavorable reaction with the free-energy change of about $11 \mathrm{kcal} /$ mol. Moreover, oxygenation transformed the weak phenolic base of $\mathrm{pK}_{\mathrm{a}}=9$ to strong alkoxide base of $\mathrm{pK}_{\mathrm{a}}=20$, and energy of approximately $15 \mathrm{kcal} / \mathrm{mol}$ is required to elevate the base strength in the reaction leading to the tertiary alkoxide. Therefore, it seems to be neither thermodynamically nor kinetically favorable in the course of oxygenation. However, thermochemical analysis in the similar oxygenation reaction reveals that heat of reaction of $-60 \mathrm{kcal} / \mathrm{mol}$ was derived for oxygenation of the naphthoxide to the corre- sponding epoxy alkoxide. ${ }^{\text {It }}$ Our model undergoes a partial combustion with molecular oxygen in the course of oxygenation and more than ample energy is available to overcome their electro-potential weakness for the superoxide formation as well as thermodynamic disadvantage for enhancement of the base strength.

Judging from the results on the theoretical investigations and control experiments, the mechanism for base-catalyzed oxygenation of phenol derivatives involves one electron reduction of molecular oxygen from phenoxides to give phenoxy radicals. This is the key intermediates for autoxidation and coupling of phenoxy radicals and superoxide radical anion to give peroxy anions and then lead the final epoxy alcohol adducts. Studies are underway to provide firmer evideness for the reaction mechanism.

Acknowledgements. This work was supported by ChungAng University (2005).

\section{References and Notes}

I. Nishinage, A.; Itahala, T.: Matsuura, T. Chem. Left. 1974, 667.

2. Demmin, T. R.; Swerdlofl, M. D.: Rogic, M. M. J. Am. Chen Soc, 1981, 103,5795

3. Matsumoto, S.; Matsio, M. J. Org. Chen. 1986, 5/, 1435.

4. Griesshammer. R; Schncider, II. P.; Winter, W.; Reiker. A Tetrahedron Lett. 1979, 41, 3941.

5. Hassanein, M.; Abdel-Hay, F. I.; El-Esawy, T. E. H. Europeon Pohmer Journal 1994, 30, 335.

6. Cilliers, J. J. I..: Singleton, V. I. J. Agric. Food Chem. 1990, 38 , 1797.

7. I lam, S. W. Dowd, P. . Am. Chem. Soc. 1990, /12, 1660

8. Dowd, P.: Ham, S. W. J. Am. Chem. Soc. 1991, 113, 9403.

9. Russe]], G. A.; Janzen, E. G; Bemis, A. G;; Geels, E. J.; Moye, A. J.; Mak. S.; Strom. F. T. Adv. Chent. Ser: 1965, 5f, II2.

10. Nakanishi, J.: Miyazaki, K.: Shimada. T.; Lizuka, Y.; Lnami, K.: Mochizuki, M.; Urano, S.: Okuda, IJ.: Ozawa, T.; Fukuzumi, S.: Ikota, N.; Fukuhara, K. Org. Biomol. Chem. 2003, 1, 4085.

11. Ham, S. W.; Lee, K. C.: Lee, K.-J.; Lim, [)-H. Bull. Kortan Chem. Sot 1996, 17,573 .

12. Newcomb, M.: Manek, B. ./. Am. Chem. Soc. 1990, /12, 9662.

13. Nishinaga, A.; Shimizu, T.: Matsuura, T. Chem. Lett. 1977, 547.

14. Frimer, A. A. The Chemistry of Finctional Groups, Peroxides; Patai, S., Ed.; Wiley: New York, 1983; p 201.

15. Grampp. G; Landgraf, S.; Muresanu, C. Flectrochimica Acta 2004, 49, 537.

16. Hlowers, R. A.; Naganathan, S.; Dowd, P.; Amell, E. M.; Ham, S. W. $J$. An. Chem. Soc. 1993, 115,9409 . 